\title{
Going with the flow:
}

Water quality and community health in Costa Rica

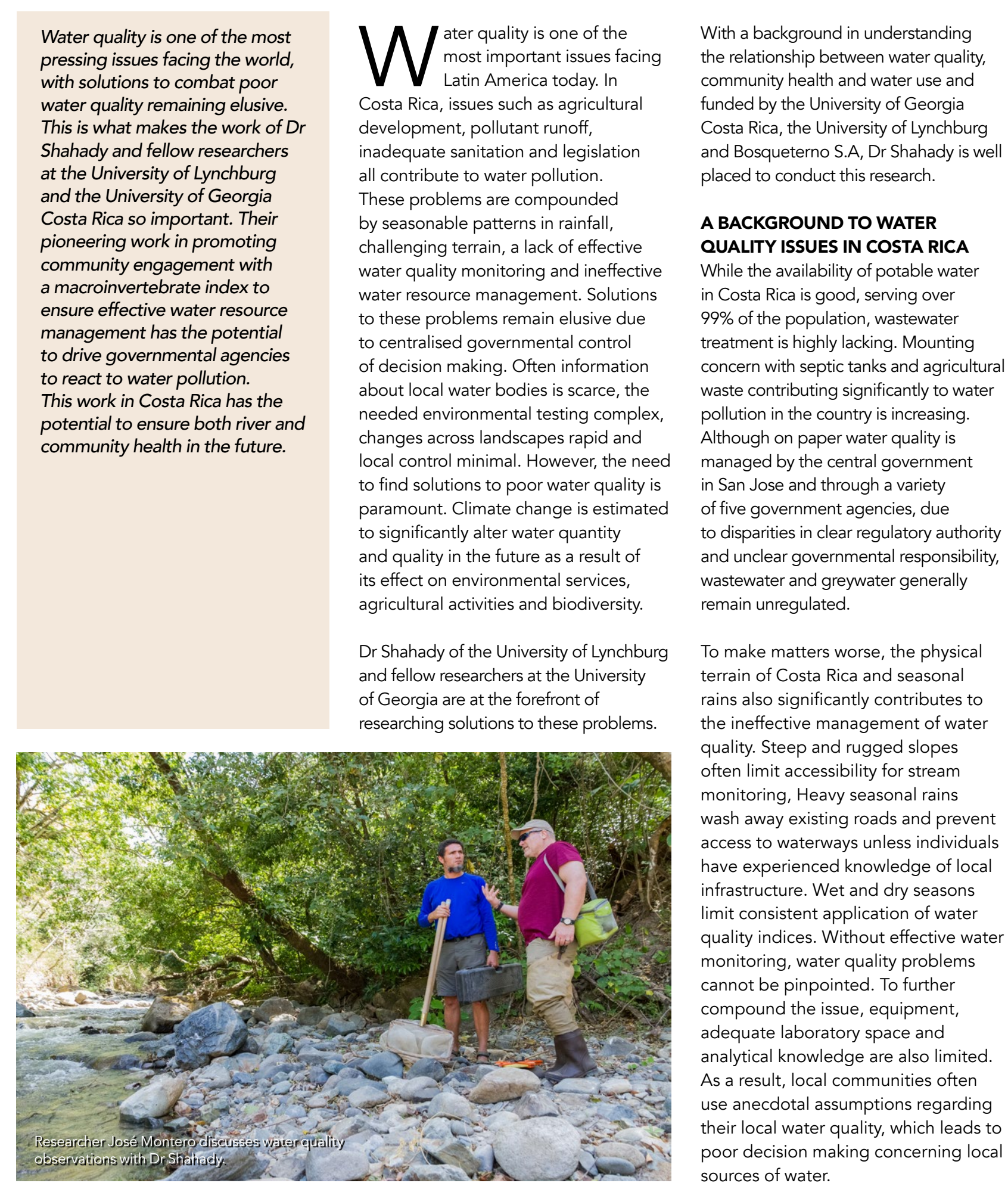

Water quality is one of the most pressing issues facing the world water quality remaining elusive. This is what makes the work of $D$ . and the University of Georgia This work in Costa Rica has the potential to ensure both river and

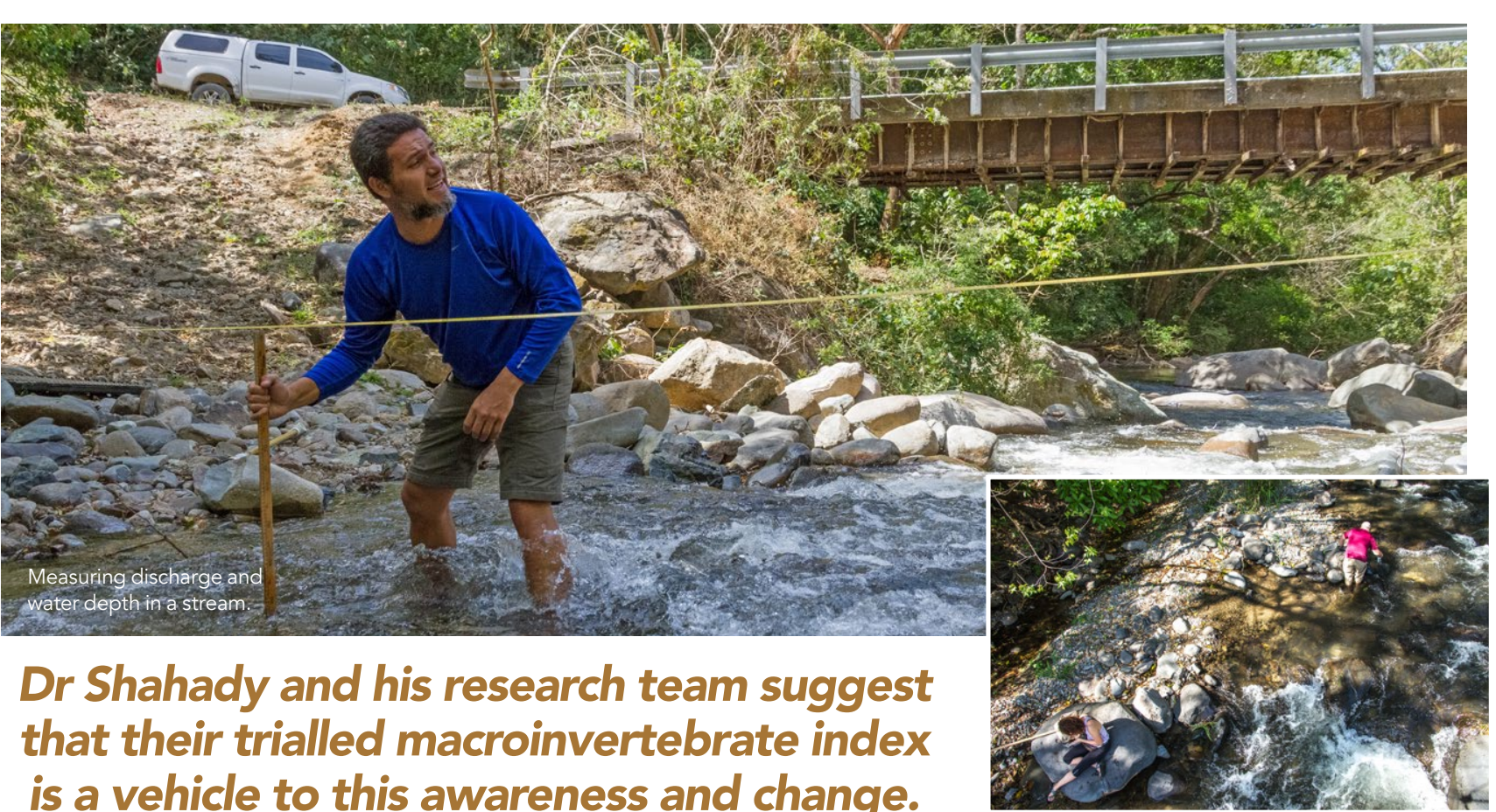

is a vehicle to this awareness and change.

\section{USING INSECTS TO}

MEASURE WATER QUALITY

To solverdable and easily measurable

methodology is needed for water qual

prediction that takes into consideration

the concerns and abilities of local

communities. One possible solution is the

use of a macroinvertebrate index. This is

a methodology whereby the ecological

condition of water bodies is inferred

using information about what insects live

there. This is already a well-established

technique for assessing the quality of

natural water bodies. The government of

Costa Rica implemented such an index

in 2007. Known as the BNWP-CR Index,

aquatic insects for water quality detection.

aquatic insects for water quality detection.

using this index Its use requires certain

ways of collecting insects and demands

expertise in insect identification skills.

Dr Shahady and his team therefore set

about testing whether an alternative and

more appropriate macroinvertebrate

index (known as the PMA Index) could be used by communities that required less expertise and knowledge.

Dr Shahady and fellow researchers set out to compare these two indices, by conducting research as part of a larger water qualy montong project in the Bellbirr Biological Corridor in Costa Rica. They tested 16 sampling sites
between 2015 and 2016. The sampling sites traversed different elevations, and community volunteers can provide water different land-use types. At each site, water quality was measured in three ways: analysis, and collecting insects for the BMWP-CR index and simpler PMA index simultaneously. This simpler PMA index was used by volunteers from local areas who used a worksheet which explained and drawings.

The simpler PMA index was found to be better at predicting water contamination (han the more complex BMWP-CR index, suggesting that the simpler index, which locals can use, is pracical as a predictor

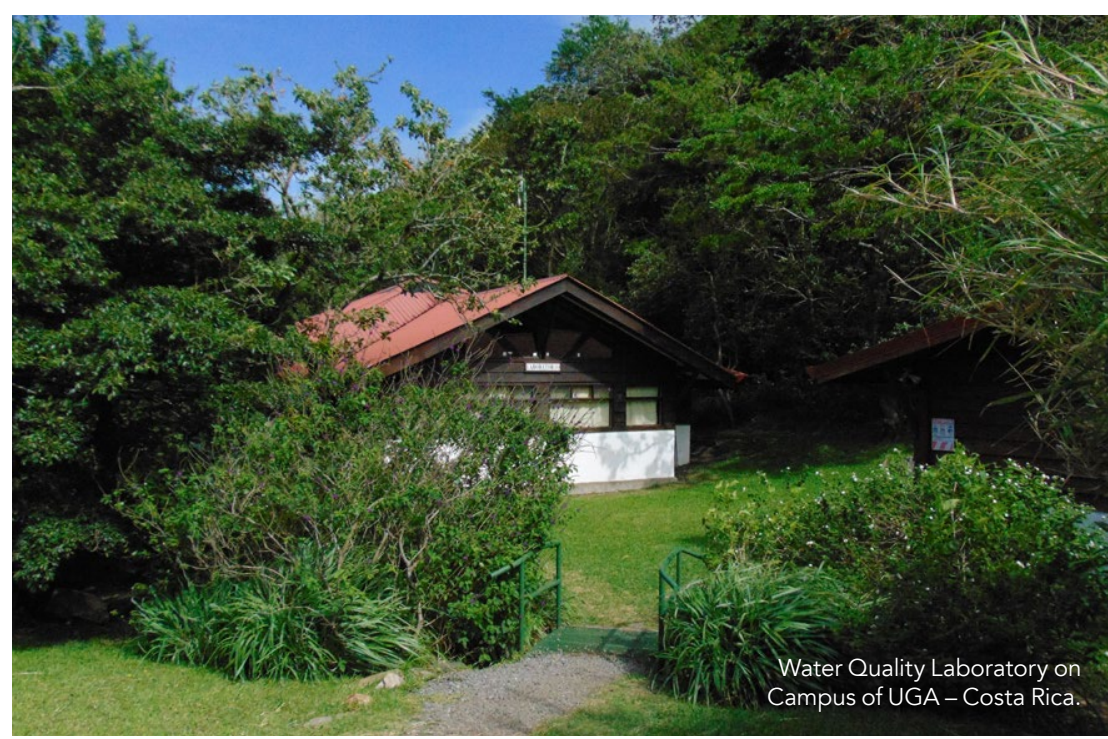




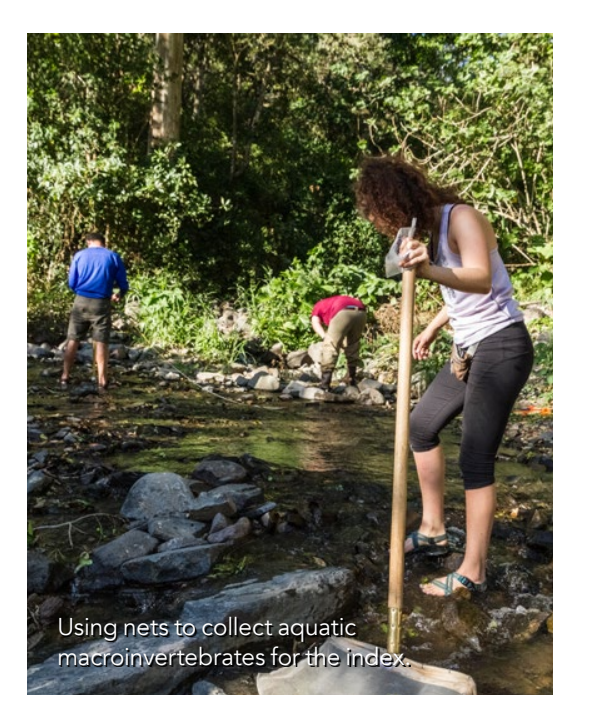

a solution. Current ones already in place in Costa Rica are currently not well maintained and future construction is very expensive. They often have unreparably buildaps of se an ock build-ups of sewage sludge. To make government agency, programme or law directly assigned to protect rivers from inadequate sanitation, despite strong evidence suggesting that improved water quality leads to reductions in disease occurrences.

Compounding the issue, climate change is expected to have a significant impact on water quality and river health in Costa Rica in the future. Models suggest that predicted increases and variability in precipitation will alter the ways that rivers flow, which means that water bodies that are currently considered to be healthy may become contaminted in the future. with groundwater is unknown. There is a real possibility that drinking water contamination may occur in Costa Rica in the next few decades.

The bottom line is that communities need with water issues to drive local and collective governments to react in order to aid public health. Dr Shahady science and their simplified index used for

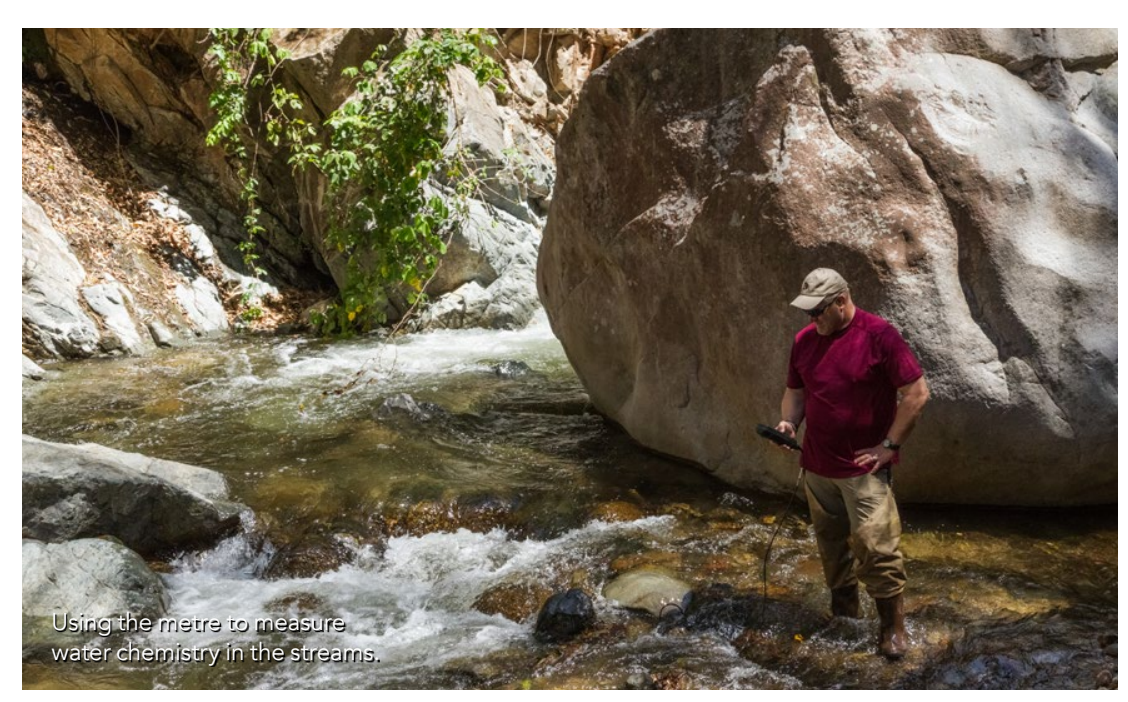

CITIZEN SCIENCE TO ENSURE COMMUNITY HEALTH

cord to protect water quality are payments are incentives offered to landowners in exchange for managing their land to provide some sort of environand service. PSA programmes focus on maintaining adequate supplies of water for purposes valued by the community such as hydroelectric power Decisions to create PSA programmes are locally made and driven by economic factor that make sense to local land-owners. But indirectly, these programmes provid improved water quality management for entire communities.

People that live in areas with PSA programmes are more likely to think posively about ho envirnment, and therefore expect better water quality. very different ideas about water quality. While they have may have concerns, they perceive government programmes as being responsible for water quality maintenance. With this perception, sources of water pollution are generally ignored, and disease risk significantly increased. However, if these pollutants were to be monitored, water quality concerns could be heightened, and about the water they are actually drinking

Community volunteers are capable of providing water quality index calculations similar to more sophisticated scientific studies.
If locals are aware of the benefits to be gained from maintaining good water qualis is is acisions to benefit themselves, Just

Dr Shahady and his research team suggest that their trialled macroinvertebrate index is a vehicte to this awareness and change. Using their group would be able to provide information otherwise unavailable to residents that may make them care more decisions about how to deal with water pollution. Areas of contamination could be identified, and this information could be used to begin an improved legal framework for river protection. Locals involved could begin to establish longefforts to improve waner qualy.

\section{THE FUTURE}

Although drinking water in Costa Rica is in adequate supply, sanitation is highly lacking. Rivers carry high levels of pollutants and could be a significant source of disease. A simple index to measure water quality, as trialled by $D$ Shahady and his team's work, may be the catalyst to change this. By monitoring their own water, Dr Shahady and his team hope that communities will work together to install management practices for agricultural and sanitary wastewater, in order so that water quality can be improved. They believe that engagement the future of water health in Costa $\mathrm{Ric}$ tested simplified index, a community about their water quality and make local and support for water monitoring practices

\section{Behind the Research}

Dr Thomas Shahady

E: shahady@lynchburg.edu T: $+14349445684 \quad$ T: $+14345448545 \quad$ W: https://www.lynchburg.edu/academics/academic community-centers/center-for-water-quality/stream-ecology-management/costa-rica/ W: https://costarica.uga.edu/ W: https://ugacostaricablog.com/2016/10/14/research-spotlight-video-water-quality-with-darixa-hernandez/

Research Objectives

Dr Shahady's research focus centres on understanding the relationship between water quality, community health and water use in Costa Rica.

\section{Detail}

1501 Lakeside Drive

Lynchburg VA 24501, USA

Bio

Dr Shahady is an Environmental Scientist and Researcher He earned his PhD from North Carolina State University in Zoology and his master's of science in public health

and engineering from UNC - Chapel Hill.

Funding

University of Georgia Costa Rica for Logistical and

Matching Support

University of Lynchburg for Direct Funding of Research - Two BESA (Bosqueterno S.A.) grants for direct financial support

\section{Collaborators}

- Researcher UGA-CR

- Fabricio Comacho Director UGA-CR

- Scott Connelly - Professor UGA

- Veronica Sheehan - Sustainability Center

$$
\text { 'थิ }
$$

University of

Lynchburg

\section{References}

Arias, A. (2010). 'Situación de Potabilización y Saneamiento en Costa Rica'. En: Decimosexto In- forme Estado de la Nación

Cosank (2014) Wano Sostenible, pp. 36.

Bower, K. (2014) 'Water supply and sanitation of Costa Rica'. Environmental Earth Sciences, Vol. 71, pp. 107-123.

Cairns, J. \& Pratt, J. (1993). 'A history of biological monitoring using benthic macroinvertebrates', in Rosenburg, D. \& Resh, $V$. (eds.) Freshwater biomonitoring and benthic
macroinvertebrates. New York: Chapman and Hall. Karmalkar, A., Bradley, R \& Diaz, H. (2011). 'Climate change in Central America and Mexico: regional climate model validation and climate change projections'. Climate Dynamics,

Kuzdak, C. \& Wiek, A. (2014). 'Governance scenarios for addressing water conflicts and climate change impacts'.
Environmental Science and Pollution Research, Vol. 42 , pp. 181-196.

Schwarzenbach, R., Egli, T., Hofstetter, T., von Gunten, U. \& ' Annual Review of Environment and Resources, Vol. 35, pp. 109-136.

Wood, M., Sheridan, R., Feagin, R., Castro, J. \& Lacher, T. (2017). 'Comparison of land use change in payments for programs'. Land Use Policy, Vol. 63, pp. 440-449.

\section{Personal Response}

What made you so interested in researching and II Teaching students of all ages and the discovery of wonderful and have helped me teach, learn and enjoy everything about Costa Rica. I wanted to give something back and use my expertise to help them solve problems. ecology and patterns of insect worldwide distribution. Discoveries in nature, ecological response to both natura and human disturbance, and teaching about living sustainably with these amazing natural resources are some
of my greatest interests. 